\title{
THE INFLUENCE OF BRADYRHIZOBIUM JAPONICUM AND AZOSPIRILLUM BRASILENSE ON THE VERTICAL MIGRATION OF NUTRIENTS AT SOYBEAN CULTIVATION
}

\author{
S. F. Kozar, I. M. Pyschur, V. M. Nesterenko
}

Nitrogen-fixing bacteria developing in plants root area are able to improve their nutrition and boost the growth and development of crops. Particularly effective are nodule bacteria that form symbiotic systems with various legumes, including soy [1]. The maximum realization of rhizobia-plant systems potential can be achieved by the incorporation of all abiotic and biotic environmental factors effect, one of which is the impact on symbiotic diazotrophs of associative or nonsymbiotic nitrogen-fixing bacteria.

There are some author's research results that indicate the possibility of root growth and nodulation stimulation in soybean plants by the use of azospirils in conjunction with the inoculation with different strains of rhizobia [2-4]. It was shown that microorganisms introduced in agrocenosis can help increase the length and dry mass of roots and growth of root hairs. The enhanced root development after the application of mixed culture of microorganisms, in our view, should provide a reduction of nutrients losses with vertical water flow by the soil profile observed in the conditions of flushing regime.

The objective of our work was to study the effect of soybean pre-seed bacterization with diazotrophs Bradyrhizobium japonicum and Azospirillum brasilense on the intensity of vertical migration of nutrients beyond the root layer of soil.

Materials and methods. The effect of soybean pre-seed bacterization on vertical migration of compounds of nutrients was studied in the terms of lysimeter installation of the Institute of Agricultural Microbiology and Agroindustrial Manufacture of NAAS, containing 48 sections-lysimeters placed in two parallel rows of 24 lysimeters each. Vessels-receivers for infiltration collection are placed beneath. By construction the lysimeters are made of concrete, bulk type. Lysimeter cells are filled with soil sequentially, beginning with the parent rock, taking into account the power of genetic horizon. Lysimeter cell cultivated area is $3.8 \mathrm{~m}^{2}$, soil layer $-155 \mathrm{~cm}$, its weight -10.5 tons. Soil in lysimeters - sod-podzolic sabulous with such agrochemical characteristics of arable layer $(0-23 \mathrm{~cm})$ : humus content by Tiurin $1.1 \%$; salt extraction $\mathrm{pH}-5.5$; hydrolytic acidity (by Kappen) - $2.5 \mathrm{mg}$ eq. Per $100 \mathrm{~g} ; \mathrm{P}_{2} \mathrm{O}_{5}$ content (by Kirsanov) - $170.0 \mathrm{mg} ; \mathrm{K}_{2} \mathrm{O}$ (by Maslova) - $62.0 \mathrm{mg}$ per $1 \mathrm{~kg}$ of soil. Experiment with soy of Lehenda variety was performed in 2014. The repetition in the experiment is quadruple. The scheme of the experiment is shown in the tables.

Nitrate content was determined by phenoldisulfonic method, ammonium content with Nesler reagent, water-soluble $\mathrm{P}_{2} \mathrm{O}_{5}$ - by Kirsanov, $\mathrm{K}_{2} \mathrm{O}$ - by flame photometric method, $\mathrm{CaO}$ and $\mathrm{MgO}$ - by complexometric method, water soluble humus - by Tiurin [5].

Harvest collection and records were performed by direct method. Statistical analysis of the results was performed by Dospiekhov [6]. The content of chlorophylls $a$ and $b$ was determined spectrophotometric method [7].

Bacterial strains B. japonicum M-8 [8] and A. brasilense 410 were used in the experiment [9]. The microorganisms were obtained from the National Collection of useful soil microorganisms of the Institute of Agricultural Microbiology and Agroindustrial Manufacture of NAAS.

The studied microorganisms were grown in the conditions of periodic cultivation on microbiological rocking at $220 \mathrm{rev} / \mathrm{min}$ and $28^{\circ} \mathrm{C}$. Seeding culture of $A$. brasilense was grown in liquid culture medium of such composition $\left(\mathrm{g} / \mathrm{dm}^{3}\right)$ : maize extract - 30.0; molasses - 30.0; $\left(\mathrm{NH}_{4}\right) 2 \mathrm{SO} 4-0.10 ; \mathrm{KH}_{2} \mathrm{PO}_{4}-$ $0.25 ; \mathrm{K}_{2} \mathrm{HPO}_{4} * 3 \mathrm{H}_{2} \mathrm{O}-0.25 ; \mathrm{MgSO}_{4} * 7 \mathrm{H} 2 \mathrm{O}-$ $0.20 ; \mathrm{CaCO}_{3}$ - 0.30. Seeding culture $B$. japonicum was grown in liquid culture medium of such composition $\left(\mathrm{g} / \mathrm{dm}^{3}\right)$ : peas seed broth 100; glucose - 10; sucrose - 5; $\left(\mathrm{NH}_{4}\right) \mathrm{SO}_{4}-1.0$; $\mathrm{KN}_{2} \mathrm{RO}_{4} \quad-0.5 ; \quad \mathrm{K}_{2} \mathrm{NRO}_{4} * 3 \mathrm{~N}_{2} \mathrm{O}-0.5 ;$ $\mathrm{MgSO}_{4} * 7 \mathrm{H}_{2} \mathrm{O}-0.2 ; \mathrm{CaCO}-0.3$. Co-culturing of $A$. brasilense and $B$. japonicum bacteria was performed using a mixed culture medium for culturing rhizobia and azospiryls [10].

We express our sincere gratitude to the 
authors for kindly furnished strains, and the staff of Agricultural Chemistry and Soil Fertility laboratory of the Institute of Agricultural Microbiology and Agroindustrial Manufacture of NAAS for assistance in the study.

The records of soybean yields showed that pre-plant inoculation of seeds with nodule bacteria helped increase the culture productivity. There was no significant effect of A. brasilense 410 on productivity. The highest increase in soybean harvest against control was observed in the variant with common use of $B$. japonicum M-8 and A. brasilense 410 (Table.
2). While combined application of rhizobia and azospiryls helped increase the yields by $19.2 \%$ compared with the use of pure $B$. japonicum culture.

Thus, the use of $B$. japonicum and $A$. brasilense in soybean growing technology there is a significant decrease in the loss of moisture, water soluble humus compounds and nutrients, and increase in the content of chlorophyll a and $b$ in leaves of soybean plants. At combined use of rhizobia and azospiryls the synergistic effect as for the increase of yields of this legume is observed. 